\title{
Evaluating the Electrochemical Characteristics of Babassu Coconut Mesocarp Ethanol Produced to Be Used in Fuel Cells
}

\author{
Ziel S. Cardoso, ${ }^{a}$ Isaide A. Rodrigues, ${ }^{*, a}$ Cáritas J. S. Mendonça, ${ }^{a}$ José R. P. Rodrigues, ${ }^{a}$ \\ Walace R. A. Ribeiro, ${ }^{a}$ Wanderson O. Silva $^{b}$ and Adeilton P. Maciel ${ }^{a}$ \\ ${ }^{a}$ Departamento de Química, Universidade Federal do Maranhão, 65080-040 São Luiz-MA, Brazil \\ ${ }^{b}$ Instituto de Química de São Carlos, Universidade de São Paulo, \\ CP 780, 13560-970 São Carlos-SP, Brazil
}

\begin{abstract}
The aim of the present study is to assess the potential of ethanol deriving from the mesocarp of babassu coconut to be used in fuel cells. Babassu ethanol was generated through hydrolysis and fermentation processes. The Pt, PtRh and PtRu electrodes were prepared in carbon Vulcan $\mathrm{XC72R}$ through the reduction method and applied as electrocatalysts in ethanol oxidation reaction. $\mathrm{X}$-Ray diffraction (XRD), energy-dispersive X-ray (EDX), stripping CO, cyclic voltammetry, chronoamperometry, and online differential electrochemical mass spectrometry (DEMS) were used to characterize the synthesized eletrocatalysts. The electrocatalyst Pt80Ru20/C presented larger active area and higher catalytic activity than other studied materials. The current efficiency of $\mathrm{CO}_{2}$ production rated less than $1 \%$ in all studied electrocatalysts, thus showing that babassu ethanol oxidation produces less pollutants than the commercial ethanol.
\end{abstract}

Keywords: babassu, ethanol oxidation, electrocatalysis

\section{Introduction}

Fossil fuel exploitation has generated great negative impacts on the environment. Fuel discharge into rivers, seas and oceans is common, a fact that results in endangered animal species, as well as in fuel burnings that release $\mathrm{CO}_{2}$ into the atmosphere. This is a major air pollutant responsible for the global warming experienced in recent decades. ${ }^{1-3}$

Research resulting from oil production issues have sought the development of technologies to generate power from renewable natural reserves, in order to produce power in a cleaner way. ${ }^{1-3}$

Accordingly, ethanol has emerged as an alternative fuel source; Brazil only produces sugarcane ethanol for commercial purposes. However, ethanol can be made from a large variety of natural and renewable sources; it is obtained through the fermentation of many raw materials such as sugarcane, corn, beet and barley. ${ }^{4}$

Babassu palm tree has great economic value, almost all its parts can be used in the food, handcrafting and power generation sectors. ${ }^{5}$ Babassu palm fruit has great economic potential since it is the raw material for a wide variety of

*e-mail: isaide.rodrigues@gmail.com products such as coal, oil, glycerin, ethanol, etc. ${ }^{5}$ Babassu coconut mesocarp ethanol emerged as an alternative to the alcohol P.A. sold by big industries.

Ethanol is a fuel derived from renewable natural sources; therefore, it became one of the main alternatives to gasoline replacement, since it is less polluting and produced on large scale from raw materials of renewable nature. ${ }^{6}$

Starch is a clean carbon source widely used as ethanol feedstock but, in turn, it derives from sugar fermentation processes performed by microorganisms such as Saccharomyces cerevisiae. ${ }^{7,8}$

Saccharomyces cerevisiae is commonly used to produce ethanol on large scale; however, this microorganism is not capable of degrading starch molecules into sugars. Thus, starch needs to pass through a hydrolysis process in order to be used as raw material in sugar ethanol. ${ }^{9}$

The starch hydrolysis process requires water and chemical, or enzymatic, agents capable of breaking glycosidic bonds. ${ }^{9}$ Starch ethanol production demands the gelatinization step, in which starch is cooked, liquefacted and saccharificated to form sugars and ferment glucose into ethanol. . $^{10,11}$

Ethanol is the most outstanding alcohol among the several ones that show direct use in fuel cells. It stands out 
mainly due to its high energy density, low toxicity and the possibility of producing it in large scale through biomass fermentation, which is a process that offers environmental and economic sustainability. ${ }^{12-14}$

In turn, the ethanol used in direct ethanol fuel cells (DEFC) is oxidized into $\mathrm{CO}_{2}$ at the anode, i.e., fuel cells convert the chemical energy from a certain fuel into electric power. ${ }^{15-17}$ Ethanol complete oxidation reaction involves the transfer of 12 electrons per ethanol molecule, which leads to the generation of many adsorbed intermediates and by-products during the oxidation process. ${ }^{17}$

The kinetics of electrochemical oxidation of ethanol is slow; ${ }^{13}$ therefore, studies have been devoted to develop catalysts to be used in the electrooxidation of this alcohol. ${ }^{13}$ Platinum-based catalysts are the most often studied for alcohol oxidation purposes. ${ }^{13,18,19}$ Platinum is a noble metal of high catalytic activity; however, it is not able to oxidize carbon monoxide $(\mathrm{CO})$ molecules into carbon dioxide $\left(\mathrm{CO}_{2}\right)$ at low power. Therefore, it requires using a second metal along with platinum to favor $\mathrm{CO}$ oxidation into $\mathrm{CO}_{2}$ at lower potentials. ${ }^{13,18}$

Metals such as rhodium and ruthenium are examples of metals commonly used along with platinum to produce electrocatalysts. These metals favor the adsorption of oxygenated species through water molecule activation, which leads to $\mathrm{CO}$ oxidation into $\mathrm{CO}_{2}$ at low potentials. Such process derives from the bifunctional mechanism or from the electronic effect. ${ }^{20-23}$ The bifunctional mechanism lies on the supply of a second metal containing oxygen species to platinum in order to oxidize the $\mathrm{CO}$ molecule into $\mathrm{CO}_{2}$ and to release platinum catalytic surface to a new adsorption. ${ }^{20,21}$ The metal added to platinum in the electronic effect modifies the platinum electronic structure and leads to bonding force decrease in the $\mathrm{CO}$ molecule of the electrocatalyst surface. ${ }^{22,23}$

The objective of the present study was to develop and apply platinum-based nanoparticles to oxidize babassu coconut mesocarp ethanol, as well as to assess the chemical and electrochemical characteristics of this ethanol type by using the cyclic voltammetry (CV), chronoamperometry and differential electrochemical mass spectroscopy (DEMS) techniques.

\section{Experimental}

\section{Synthesis of electrocatalysts}

The electrocatalysts Pt/C 20\%, Pt80Rh20/C and $\mathrm{Pt} 80 \mathrm{Ru} 20 / \mathrm{C}$ were prepared through the alcohol reduction method, also known as polyol method, which is easy to be performed and allows nanoparticles to be produced in nanometer scale. ${ }^{19}$ The electrocatalysts were synthesized in
$20 \%$ of metal mass and $80 \%$ Vulcan XC72R (Cabot) carbon support. The Vulcan carbon was treated with $5.0 \mathrm{~mol} \mathrm{~L}^{-1}$ $\mathrm{HNO}_{3}$ in a reflux system for $5 \mathrm{~h}$ at a controlled temperature between $70-80^{\circ} \mathrm{C}$. After the reflux, the Vulcan carbon was washed with deionized water until $\mathrm{pH} 5$ was reached (the water was distilled in a Fanem distiller model 724 and purified $(18.2 \mathrm{~m} \Omega \mathrm{cm}$ ) in a Millipore Milli-Q Academic system). The solid phase retained in the filter was then placed in an oven at $60{ }^{\circ} \mathrm{C}$ for $24 \mathrm{~h} .{ }^{19}$

Platinum, rhodium and ruthenium impregnation into the treated Vulcan carbon occurred due to the addition of precursor salt solutions and of an ethylene glycol/water solution $(75 / 25, v / v)$. Such addition was conducted in order to get to the desired mass of each metal. ${ }^{19}$ The mixture was subjected to reflux system at controlled temperature (between 70 and $80^{\circ} \mathrm{C}$ ) for $2 \mathrm{~h}$. The mixture was washed and filtered after reflux. The resulting solid phase was oven-dried at $70{ }^{\circ} \mathrm{C}$ for $24 \mathrm{~h}$, then macerated and stored. ${ }^{19,24}$

\section{Catalytic suspensions and electrochemical cell}

Catalytic suspensions were prepared with $5.0 \mathrm{mg}$ of electrocatalyst, $1.0 \mathrm{~mL}$ of methanol due to its high volatility, $100 \mu \mathrm{L}$ of Nafion and $1.4 \mathrm{~mL}$ of deionized water. It remained in ultrasound for $30 \mathrm{~min}$ to completely homogenize the mixture. ${ }^{25}$

The working electrode surface (vitreous carbon) was polished before catalytic suspension deposition through diamond spray, a water soluble spray manufactured with monocrystalline dimond powder. Next, it was washed in deionized water and left to dry. A total of $20 \mu \mathrm{L}$ of catalytic suspension was added to the surface of the working electrode; the solvent was evaporated through hot air flow, using a hair dryer.

\section{Methods to set the physico-chemical characteristics}

\section{X-Ray diffraction (XRD)}

The X-ray diffractograms were taken in Rigaku diffractogram model ULTIMA IV by using $\mathrm{Cu} \mathrm{K} \alpha$ radiation. The crystallite sizes and network parameters of the electrocatalysts were calculated based on XRD analysis results of the plane (220) of the platinum face-centered cubic (fcc) through Scherrer's equations 1 and 2 , respectively: ${ }^{24,25}$

$$
\begin{aligned}
& \mathrm{d}=\frac{\mathrm{k} \lambda_{\mathrm{k} \alpha}}{\mathrm{B}_{2 \theta} \cos \theta} \\
& \mathrm{p}=\frac{\sqrt{2 \lambda}}{\sin \theta}
\end{aligned}
$$


wherein $\mathrm{d}$ is the mean crystallite size; $\mathrm{p}$ is the lattice parameter; $\lambda$ is the wavelength of the used radiation, in which $\mathrm{Cu} \mathrm{K} \alpha$ is equal to $1.54056 \AA$; $\mathrm{k}$ is a constant equal to 0.9 , when the crystallites are assumed to have spherical morphology; $\mathrm{B}_{2 \theta}$ is diffraction peak width at half height in radian; and $\theta$ is the Bragg angle, in degrees, to the maximum height point of the analyzed peak. ${ }^{25}$

\section{Energy-dispersive X-ray (EDX)}

Electrocatalyst atomic compositions were set through $\mathrm{X}$-ray dispersive energy analysis conducted in the scanning electron microscope Phenom-World ProX.

\section{CO stripping}

Electrocatalyst active areas were set according to the CO stripping method. ${ }^{25,26}$ The adopted system was the same one used in cyclic voltammetric analysis, although it was performed in exhaust hood. The $\mathrm{CO}$ was bubbled into the supporting electrolyte solution for $5 \mathrm{~min}$, next, nitrogen was bubbled for 10 min. ${ }^{25,26}$ The method has been used since $1960^{26}$ and allows to determine the electric charge $(\mathrm{mC})$ required to remove $\mathrm{CO}$ monolayers from the surface of catalysts during an anode oxidation. ${ }^{25,26}$

\section{Cyclic voltammetry and chronoamperometry}

Cyclic voltammetry and chronoamperometry were performed in an Autolab PGSTATXX (Metrohm) equipment coupled to a computer. Electrocatalyst voltammograms were taken in a one-chamber electrochemical glass cell containing a reference hydrogen electrode (RHE) prepared with the same sulfuric acid solution used as electrolyte carrier, as well as with a working (glassy carbon), a counter and a platinum electrodes. Ethanol electrooxidation studies were carried out in $0.1 \mathrm{~mol} \mathrm{~L}^{-1}$ ethanol solutions in $0.5 \mathrm{~mol} \mathrm{~L}^{-1} \mathrm{H}_{2} \mathrm{SO}_{4}$ medium at range $0.03-1.0 \mathrm{~V}$, and scanning speed $10 \mathrm{mV} \mathrm{s}^{-1}$ in system purged with $\mathrm{N}_{2} \cdot{ }^{19}$

\section{Online DEMS}

The online DEMS analysis was performed according to the methodology described in the literature, ${ }^{27}$ with a single compartment cell with input for the electrodes: work, auxiliary and reference, plus gas inlet and temperature controller.

The electrodes were prepared through sputter deposition (gold) on a Teflon membrane (50 nm thick) for the DEMS analysis. The Teflon membrane was added with $180 \mu \mathrm{L}$ of aqueous suspension containing the catalytic material. A mixture containing $2 \mathrm{mg}$ of catalyst powder and $25 \mu \mathrm{L}$ of Nafion was done to assure catalytic material adhesion. ${ }^{27}$

Volatiles deriving from babassu coconut mesocarp ethanol oxidation were monitored according to $\mathrm{m} / \mathrm{z} 44$ and 22 , which correspond to the ionized $\left[\mathrm{CO}_{2}\right]^{+}$and doubly ionized $\left[\mathrm{CO}_{2}\right]^{2+}$, in addition to the acetaldehyde signals $\mathrm{m} / \mathrm{z}, 29$ and 44, which correspond to $\left[\mathrm{CHO}^{+}\right.$and $\left[\mathrm{CH}_{3} \mathrm{CHO}\right]^{+}$, respectively. It was decided to monitor $\mathrm{CO}_{2}$ and acetaldehyde formation through $\mathrm{m} / \mathrm{z} 22$ and 29, which correspond to the species $\left[\mathrm{CO}_{2}\right]^{2+}$ and $[\mathrm{CHO}]^{+}$, respectively, since the $m / z, 44$ signal may correspond to the ionized $\left[\mathrm{CO}_{2}\right]^{+}$and $\left[\mathrm{CH}_{3} \mathrm{CHO}\right]^{+}$species..$^{27,28}$

\section{Results and Discussion}

Physico-chemical characterization of the synthesized eletrocatalysts

XRD

Diffractograms of metal alloys Pt80Rh20/C, Pt80Ru20/C and $\mathrm{Pt} / \mathrm{C}$ are shown in Figure 1. Peaks at approximately $2 \theta=39,45,67$ and $81^{\circ}$ are assigned to planes (111), (200), (220), and (311), respectively, of platinum face-centered cubic (fcc) and of platinum containing metal alloys. ${ }^{24,25}$

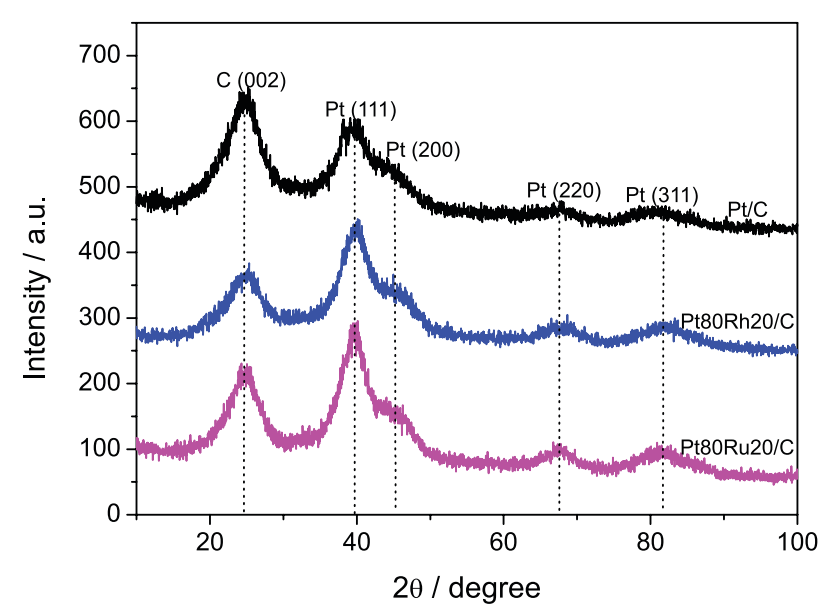

Figure 1. X-ray diffractograms of the electrocatalysts Pt/C, Pt80Rh20/C and Pt80Ru20/C.

Electrocatalyst crystallite sizes and the lattice parameters were calculated based on the peak associated with the platinum plane (220), because this plane is less influenced by the carbon carrier $\mathrm{C}(002) .^{25}$

The mean crystallite size values of each electrocatalyst are shown in Table 1. It is possible to notice that the crystallite sizes of the bimetallic electrocatalysts are smaller than those of the $\mathrm{Pt} / \mathrm{C}$ monometallic electrocatalyst. Therefore, the bimetallic electrocatalysts have larger surface areas and, consequently, more catalytic activity. ${ }^{24,28}$

Lattice parameters values are shown in Table 1. These results evidence that bimetallic electrocatalysts record lower net parameter values than the $\mathrm{Pt} / \mathrm{C}$ monocatalyst. Such result indicates Pt80Rh20/C and Pt80Ru20/C formation. ${ }^{24}$ 
Table 1. Lattice parameters and crystallite size of electrocatalysts Pt/C, Pt80Rh20/C and Pt80Ru20/C

\begin{tabular}{lcc}
\hline Electrocatalyst & Lattice parameter / & Crystallite size / nm \\
\hline $\mathrm{Pt} / \mathrm{C}$ & 3.975 & 4.1185 \\
$\mathrm{Pt} 80 \mathrm{Rh} 20 / \mathrm{C}$ & 3.933 & 3.5001 \\
$\mathrm{Pt} 80 \mathrm{Ru} 20 / \mathrm{C}$ & 3.961 & 3.8211 \\
\hline
\end{tabular}

The lattice parameters values of the electrocatalysts are similar to those found in literature, ${ }^{24,28}$ which used catalysts prepared through the alcohol reduction method to assess ethanol oxidation.

\section{EDX}

Synthesized and evaluated electrocatalyst compositions were defined through the EDX technique, which allows us to evaluate the atomic composition of a compound in a given region of the sample (Table 2). Because EDX is a point technique, it gives us indications about the content of chemical elements found in a certain point of the sample studied.

Table 2. Experimental compositions of Pt/C, Pt80Rh20/C and Pt80Ru20/C electrocatalysts set through EDX

\begin{tabular}{lc}
\hline Nominal atomic composition / \% & $\begin{array}{c}\text { Experimental atomic } \\
\text { composition (EDX) / \% }\end{array}$ \\
\hline $\mathrm{Pt}$ & - \\
Pt80Rh20 & Pt71Rh29 \\
Pt80Ru20 & Pt81Ru19 \\
\hline
\end{tabular}

EDX: energy-dispersive X-ray.

\section{Electrochemical characterization of synthesized electrocatalysts}

Determining the active areas of electrocatalysts through CO stripping

Figure 2 shows the $\mathrm{CO}$ adsorption cyclic voltammograms of different electrocatalysts in $0.5 \mathrm{~mol} \mathrm{~L}^{-1} \mathrm{H}_{2} \mathrm{SO}_{4}$ solution.

It was possible to set the active areas of the electrodes (AAE) through equation 3 based on the electrical charges of adsorbed $\mathrm{CO}\left(\mathrm{CO}_{\text {ads }}\right)$ (Table 3 ) found after integrating the highlighted areas in the voltammograms. ${ }^{25,26}$

$\mathrm{AAE}=\frac{\mathrm{Q}_{\mathrm{CO}_{\mathrm{ads}}}}{\mathrm{Q}_{\mathrm{CO}}}$

wherein $\mathrm{Q}_{\mathrm{CO}_{\text {ads }}}(\mathrm{mC})$ is the $\mathrm{CO}$ adsorption charge of the cyclic voltammetries in Figure 2; and $\mathrm{Q}_{\mathrm{CO}}$ is the theoretical electrical charge required to oxidize a $\mathrm{CO}$ monolayer in $\mathrm{Pt}\left(420 \mu \mathrm{C} \mathrm{cm}{ }^{-2}\right) .{ }^{26}$ Determination through the cyclic
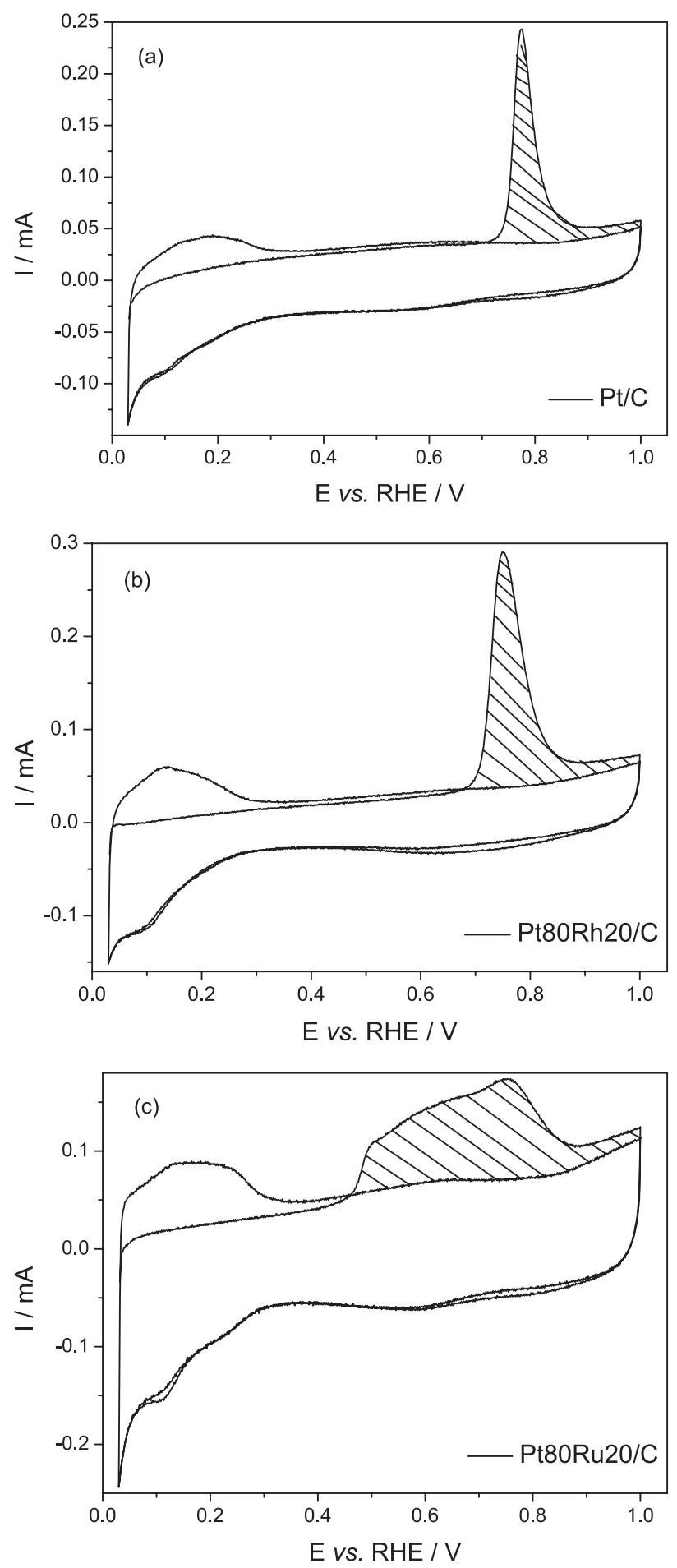

Figure 2. Cyclic voltammetry to find the active areas in the studied electrocatalysts: (a) Pt/C, (b) Pt80Rh20/C and (c) Pt80Ru20/C in $0.5 \mathrm{~mol} \mathrm{~L}^{-1} \mathrm{H}_{2} \mathrm{SO}_{4}, 10 \mathrm{mV} \mathrm{s}^{-1}$ scan rate, purged by $\mathrm{CO}$ and $\mathrm{N}_{2}$ for 5 and $10 \mathrm{~min}$, respectively.

voltammetry of the amount of charge (Table 3 ) required to oxidize a $\mathrm{CO}$ monolayer adsorbed by a platinum electrode must take into consideration that the $\mathrm{CO}$ molecule is adsorbed by each platinum atom. ${ }^{25,26}$ The determined AAE values are shown in Table 3 . Alcohol oxidation in the fuel 
cell may present higher catalytic sample activity ${ }^{24}$ in the case of bimetallic catalysts.

Table 3. Load needed to oxidize CO (C) monolayer and to activate electrocatalysts areas determined through CO stripping

\begin{tabular}{lcc}
\hline Electrocatalyst & $\mathrm{CO}_{\text {ads }} / \mathrm{C}$ & $\mathrm{AAE} / \mathrm{cm}^{2}$ \\
\hline $\mathrm{Pt}$ & $1.16 \times 10^{-3}$ & 2.76 \\
Pt80Rh20 & $2.00 \times 10^{-3}$ & 4.76 \\
Pt80Ru20 & $2.97 \times 10^{-3}$ & 7.07 \\
\hline
\end{tabular}

$\mathrm{CO}_{\text {ads }}$ : adsorbed CO; AAE: active areas of the electrodes.

\section{Electrocatalytic performance}

Figure 3 shows the cyclic voltammetry curves of different electrocatalysts supported on Vulcan carbon in $0.5 \mathrm{~mol} \mathrm{~L}^{-1} \mathrm{H}_{2} \mathrm{SO}_{4}$ medium, in absence of ethanol. The profile of the synthesized bimetallic electrocatalysts presents the hydrogen region $(0.03-0.4 \mathrm{~V})$ in a much more clear fashion than the monometallic electrocatalyst; there are peaks showing hydrogen adsorption and desorption..$^{12,24}$

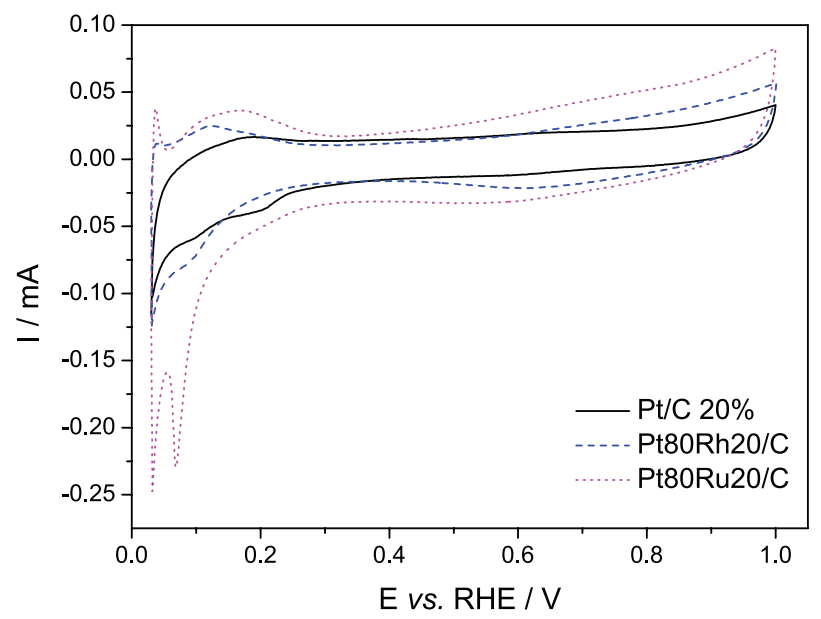

Figure 3. Cyclic voltammograms of $\mathrm{Pt} / \mathrm{C}, \mathrm{Pt} 80 \mathrm{Rh} 20 / \mathrm{C}$ and Pt80Ru20/C electrocatalysts in $0.5 \mathrm{~mol} \mathrm{~L}^{-1} \mathrm{H}_{2} \mathrm{SO}_{4}$ medium in absence of ethanol.

The bimetal electrocatalysts supported on Vulcan carbon Pt80Rh20/C and Pt80Ru20/C showed slight increase in currents in the electric double layer (0.4-0.8 V) region in comparison with the $\mathrm{Pt} / \mathrm{C}$ monometallic catalyst. Oxides formed on the catalyst surface, due to the addition of other metal to platinum in the catalyst composition, helped increase the active area of the synthesized electrocatalysts and, consequently, gave them greater oxidative power. ${ }^{12,24}$

Figure 4 shows the voltammetric profiles of different electrocatalysts (Pt/C, Pt80Rh20/C and Pt80Ru20/C) deposited on Vulcan carbon in the presence of $0.1 \mathrm{~mol} \mathrm{~L}^{-1}$ commercial ethanol (Figure 4a) and $0.1 \mathrm{~mol} \mathrm{~L}^{-1}$ babassu ethanol (Figure $4 \mathrm{~b}$ ). The current densities were normalized by the electrocatalytic surfaces of the electrocatalysts, which were estimated through the electrooxidation of a $\mathrm{CO}$ monolayer adsorbed on the working electrode.
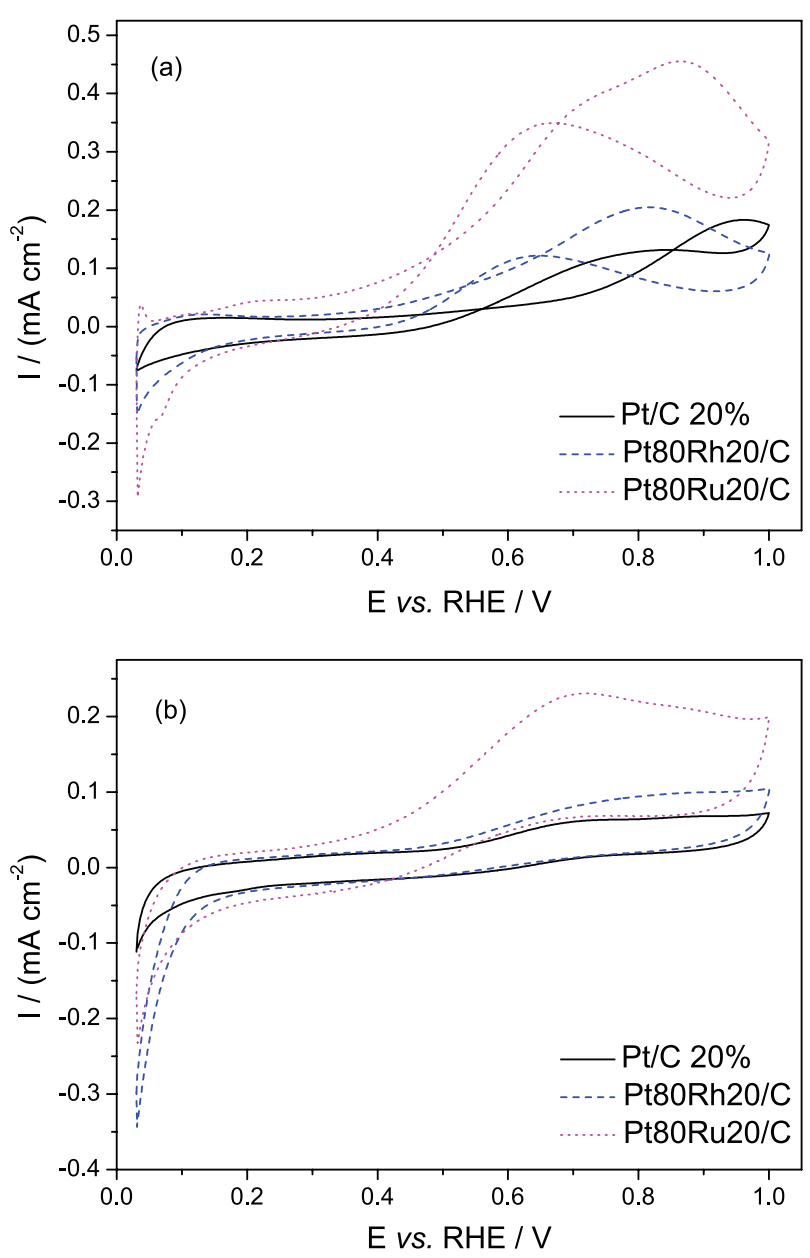

Figure 4. Cyclic voltammograms of electrocatalysts Pt/C, Pt80Rh20/C and Pt80Ru20/C in (a) $0.1 \mathrm{~mol} \mathrm{~L}^{-1}$ commercial ethanol and (b) $0.1 \mathrm{~mol} \mathrm{~L}^{-1}$ babassu coconut mesocarp ethanol, in $0.5 \mathrm{~mol} \mathrm{~L}^{-1} \mathrm{H}_{2} \mathrm{SO}_{4}$ solution at a scan rate $10 \mathrm{mV} \mathrm{s}^{-1}$, purged with $\mathrm{N}_{2}$.

Data in Table 4 evidenced that the electrocatalyst Pt80Ru20/C proved to be more efficient in the oxidation of both herein studied alcohols (babassu and commercial ethanols). The process triggers oxidation at potentials lower than that of other electrocatalysts: approximately $100 \mathrm{mV}$ less than the platinum monometallic electrocatalyst; besides, it presents higher current density in the studied alcohols. Similar results were recorded by Ribeiro et al. ${ }^{12}$

In order to determine the oxidation initiation potential in all catalysts, the point where no current oscillation occurs was verified. From this point, the current went up until the complete oxidation of the products.

Figure 4 shows that the maximum current density in all electrocatalysts of the babassu coconut mesocarp ethanol occurs in potentials lower than $0.8 \mathrm{~V}$, while for commercial ethanol, the maximum current occurs only after $0.8 \mathrm{~V}$. 
Table 4. Initial oxidation potential and current at potential $0.6 \mathrm{~V}$ in electrocatalysts $\mathrm{Pt} / \mathrm{C}, \mathrm{Pt} 80 \mathrm{Rh} 20 / \mathrm{C}$ and $\mathrm{Pt} 80 \mathrm{Ru} 20 / \mathrm{C}$ in commercial ethanol medium and $0.1 \mathrm{~mol} \mathrm{~L}^{-1}$ babassu ethanol in $0.5 \mathrm{~mol} \mathrm{~L}^{-1} \mathrm{H}_{2} \mathrm{SO}_{4}$

\begin{tabular}{|c|c|c|c|}
\hline Alcohol & Electrocatalyst & $\begin{array}{c}\text { Start of } \\
\text { oxidation / V }\end{array}$ & $\begin{array}{c}\text { Current at } \\
\text { potential } 0.6 \mathrm{~V} / \\
\mathrm{mA}\end{array}$ \\
\hline \multirow{3}{*}{$\begin{array}{l}\text { Commercial } \\
\text { ethanol }\end{array}$} & $\mathrm{Pt} / \mathrm{C}$ & 0.29 & 0.03 \\
\hline & $\mathrm{Pt} 80 \mathrm{Rh} 20 / \mathrm{C}$ & 0.23 & 0.10 \\
\hline & $\mathrm{Pt} 80 \mathrm{Ru} 20 / \mathrm{C}$ & 0.15 & 0.25 \\
\hline \multirow{3}{*}{$\begin{array}{l}\text { Ethanol from } \\
\text { babassu }\end{array}$} & $\mathrm{Pt} / \mathrm{C}$ & 0.26 & 0.04 \\
\hline & $\mathrm{Pt} 80 \mathrm{Rh} 20 / \mathrm{C}$ & 0.19 & 0.06 \\
\hline & $\mathrm{Pt} 80 \mathrm{Ru} 20 / \mathrm{C}$ & 0.15 & 0.18 \\
\hline
\end{tabular}

According to Pech-Rodrígues et al. ${ }^{25}$ who assessed ethanol oxidation, the ethanol molecule undergoes complex molecule dissociation and adsorption mechanisms, $\mathrm{C}-\mathrm{C}$ binding breakage and dehydrogenation to achieve complete ethanol oxidation into $\mathrm{CO}_{2}$. There is intermediate formations such as carboxylic acid, aldehyde and carbon monoxide, which poison the Pt catalyst. ${ }^{25,28}$

Ethanol equilibrium equations 4-6 in acidic medium, with main products and the balance of generated electrons are herein presented. ${ }^{17,25,27}$

$$
\begin{aligned}
& \mathrm{CH}_{3} \mathrm{CH}_{2} \mathrm{OH} \rightarrow \mathrm{CH}_{3} \mathrm{CHO}+2 \mathrm{H}^{+}+2 \mathrm{e}^{-} \\
& \mathrm{CH}_{3} \mathrm{CH}_{2} \mathrm{OH}+\mathrm{H}_{2} \mathrm{O} \rightarrow \mathrm{CH}_{3} \mathrm{COOH}+4 \mathrm{H}^{+}+4 \mathrm{e}^{-} \\
& \mathrm{CH}_{3} \mathrm{CH}_{2} \mathrm{OH}+3 \mathrm{H}_{2} \mathrm{O} \rightarrow 2 \mathrm{CO}_{2}+12 \mathrm{H}^{+}+12 \mathrm{e}^{-}
\end{aligned}
$$

The electrocatalyst presenting the highest electric current density was the bimetallic electrocatalyst Pt80Ru20/C in the two studied alcohols; this electrocatalyst showed its high catalytic power. On the other hand, the Pt/C monometallic electrode presented lower electrical current density in the oxidation of both alcohols.

However, the catalytic activity of an electrocatalyst is given by the potential in which the alcohol redox process is triggered, i.e., the lower the oxidation/reduction initiation potential, the greater its catalytic power. ${ }^{19}$ It is known that the Pt/C monometallic electrocatalyst is not a good oxidizing agent to electrooxidize ethanol, because of the poisoning caused by the strong adsorption of reaction intermediates such as $\mathrm{CO}_{\text {ads }}{ }^{12,29}$ Thus, the monometallic catalyst was the least efficient synthesized catalyst against alcohol oxidation reaction among all the synthesized ones. It initiated oxidation at potentials above $0.25 \mathrm{~V}$, thus revealing that the use of other metal next to platinum on the carbon support significantly increases the catalytic power of the electrocatalyst and decreases the cost with rare earth metals. ${ }^{29}$

Assumingly, both herein assessed alcohols have very similar profiles, their oxidation starts at very close potentials in all the synthesized electrocatalysts tested in the present study.

\section{Chronoamperometry}

Electrode equilibrium time at $0.6 \mathrm{~V}$ potential and electrocatalyst poisoning in active areas of continuous operation for $15 \mathrm{~min}$ were assessed through chronoamperometry analysis. Figure 5 shows how the chronoamperometry curves (current density $v s$. time) of different synthesized electrocatalysts have their current density normalized by the active area of the respective electrodes.
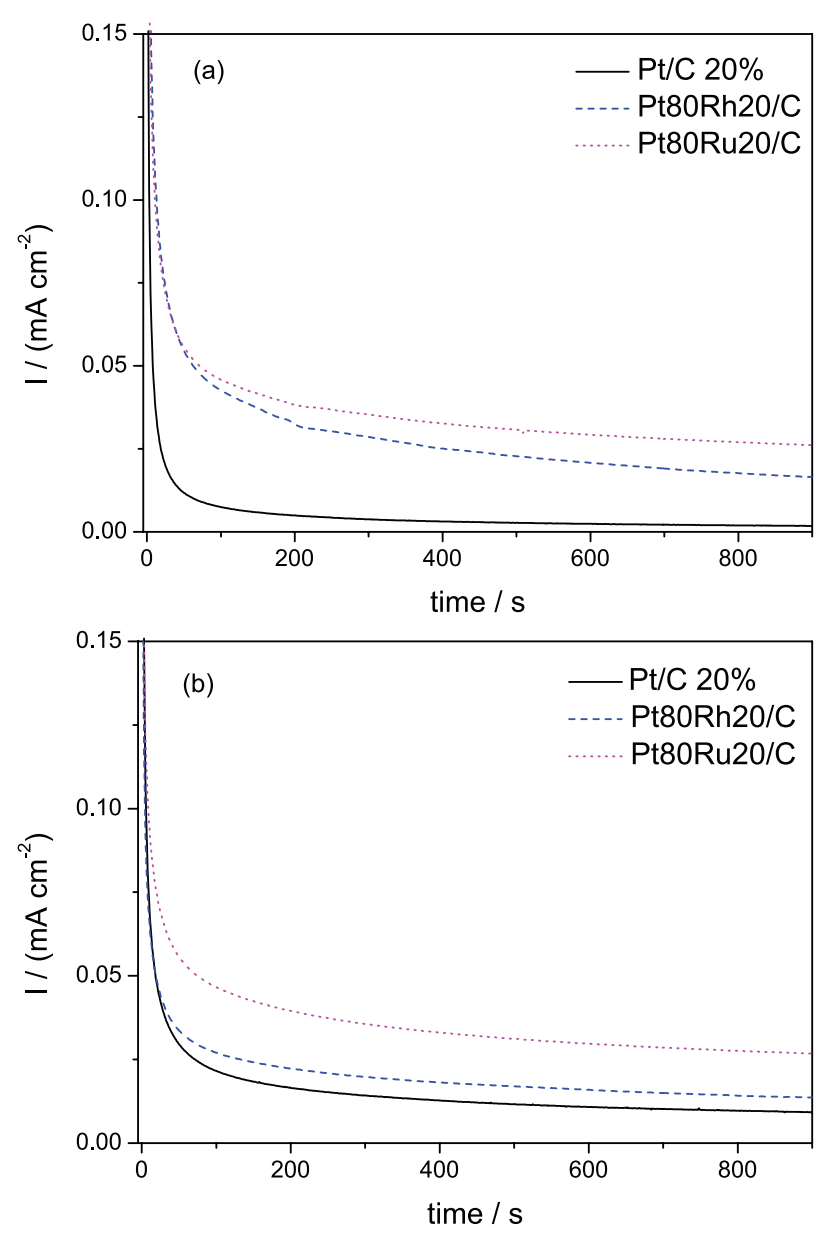

Figure 5. Chonoamperometry curves at $0.60 \mathrm{~V} v s$. RHE, for an experiment of $15 \mathrm{~min}$, purged with $\mathrm{N}_{2}$, for different eletrocatalysts in $0.5 \mathrm{~mol} \mathrm{~L}^{-1}$ $\mathrm{H}_{2} \mathrm{SO}_{4}+0.1 \mathrm{~mol} \mathrm{~L}^{-1}$ ethanol: (a) commercial ethanol and (b) babassu coconut mesocarp ethanol.

The curves of the assessed commercial ethanol and babassu seen in Figure 5 show remarkable decay in the electric current density during the first seconds of 
the analysis. Such decay was followed by slow decay throughout the following minutes; however, it remained constant during the remaining analysis time.

Ribeiro et al. ${ }^{12}$ studied alcohol oxidation and concluded that ethanol molecules can be adsorbed onto sites that were initially covered by water molecules at potentials below $0.4 \mathrm{~V}$. After adsorption, the ethanol molecule can dissociate itself and produce $\mathrm{CO}$ molecules strongly adsorbed by the electro surface along with other reaction intermediates. Oxygenated species, such as $\mathrm{OH}_{\text {ads }}$, adsorbed by the electrode surface are necessary for the ethanol molecule to be completely oxidized, a fact that leads to $\mathrm{CO}_{2}$ formation or to the formation of acetic acid molecules. ${ }^{3,12}$

Results of the chronoamperometry analysis validate the herein conducted cyclic voltammetry analysis, since the electrode with the highest electric current density in the commercial ethanol oxidation was the electrocatalyst $\mathrm{Pt} 80 \mathrm{Ru} 20 / \mathrm{C}$, followed by Pt80Rh20/C and Pt/C. The same was recorded for babassu mesocarp ethanol oxidation, in which the Pt80Ru20/C electrode recorded the highest electrical current density, followed by the Pt80Rh20/C and $\mathrm{Pt} / \mathrm{C}$ electrodes. These results follow the same order of cyclic voltammetric analysis at $0.6 \mathrm{~V}$ potential, which is used in chronoamperometry studies.

\section{Online DEMS of babassu coconut mesocarp ethanol}

Load signal $\mathrm{m} / \mathrm{z} 22$ calibration was necessary to quantify part of the total electrooxidation current of ethanol into $\mathrm{CO}_{2}$, according to results recorded through online DEMS. ${ }^{3,27,28,30,31}$ Figure 6 shows the stripping of $\mathrm{CO}$ results from acidic medium, $0.5 \mathrm{~mol} \mathrm{~L}^{-1} \mathrm{H}_{2} \mathrm{SO}_{4}, 10 \mathrm{mV} \mathrm{s}^{-1}$, of the used electrocatalysts. The $\mathrm{CO}$ stripping was used as electrochemical reaction reference, since the number of electrons exchanged during $\mathrm{CO}$ electrooxidation adsorbed by the surface of the working electrode, $\mathrm{CO}_{2}$ is already well known, as can be observed in equation $7 . .^{30,32}$

$$
\mathrm{CO}_{\text {ads }}+\mathrm{H}_{2} \mathrm{O} \rightarrow \mathrm{CO}_{2}+2 \mathrm{H}^{+}+2 \mathrm{e}^{-}
$$

Figure 6 shows the signals of the $m / z 22$ and 44 analyzed through DEMS during the acid stripping of $\mathrm{CO}, 0.5 \mathrm{~mol} \mathrm{~L}^{-1} \mathrm{H}_{2} \mathrm{SO}_{4}, 10 \mathrm{mV} \mathrm{s}^{-1}$. The $\mathrm{m} / z, 22$ signal is attributed to doubly ionized $\mathrm{CO}_{2}\left(\left[\mathrm{CO}_{2}\right]^{2+}\right)$ production during the electrooxidation of ethanol in the online electrochemical mass spectrometry. ${ }^{28,30,31}$ The $\mathrm{m} / \mathrm{z}, 44$ signal is also used in the literature to quantify ionized $\mathrm{CO}_{2}\left(\left[\mathrm{CO}_{2}\right]^{+}\right)$; however, this signal is also attributed to acetaldehyde $\left(\left[\mathrm{CH}_{3} \mathrm{CHO}\right]^{+}\right)$. Therefore, the $\mathrm{m} / z 22$ signal was used in order to not compromise $\mathrm{CO}_{2}$ quantification results. $28,30,31$
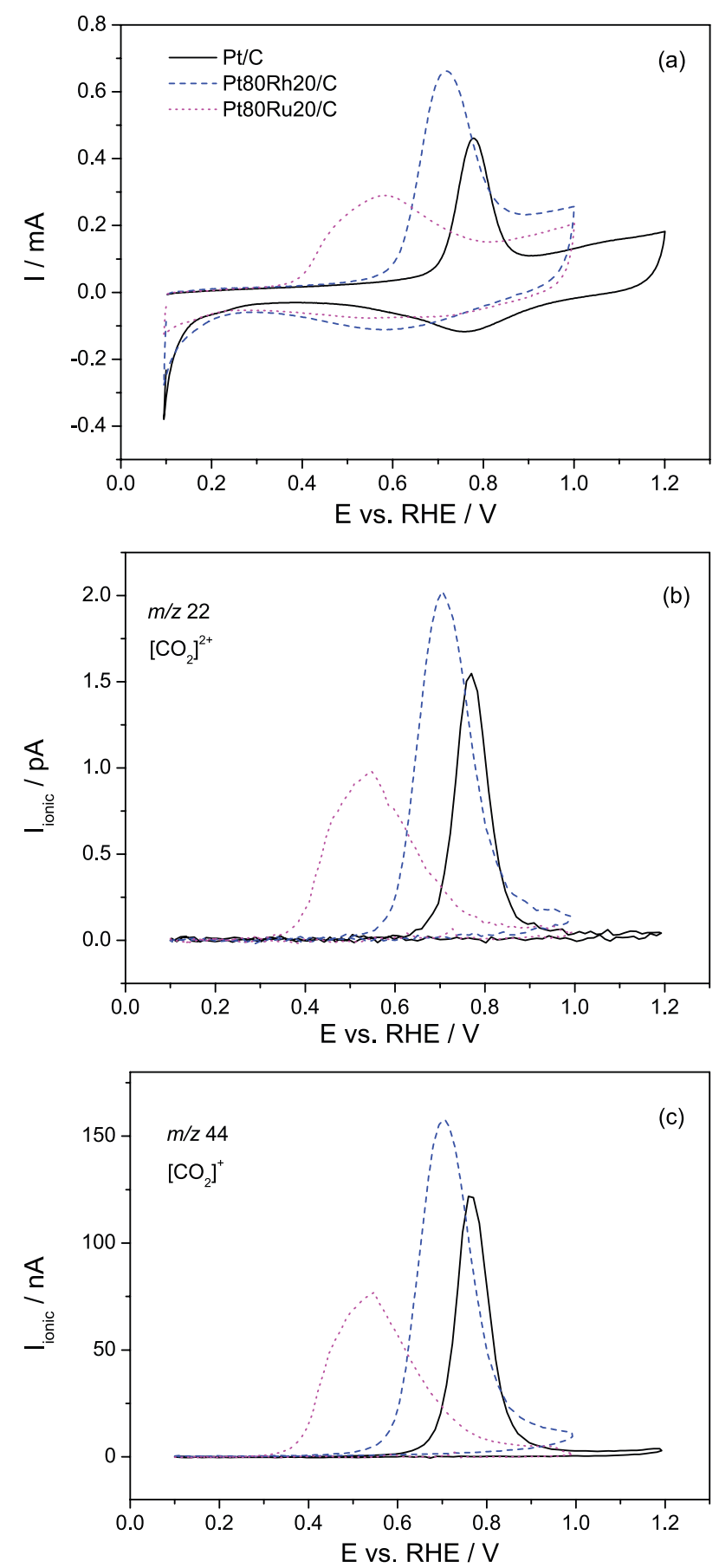

Figure 6. (a) $\mathrm{CO}$ stripping faradaic currents of electrocatalysts synthesized in $0.5 \mathrm{~mol} \mathrm{~L}^{-1} \mathrm{H}_{2} \mathrm{SO}_{4}$ medium and ionic currents of (b) $\left[\mathrm{CO}_{2}\right]^{2+}(\mathrm{m} / z, 22)$ and (c) $\left[\mathrm{CO}_{2}\right]^{+}(\mathrm{m} / \mathrm{z}, 44)$ signals.

The ionic currents of signal $\mathrm{m} / \mathrm{z} 22$ and the faradaic current recorded through stripping of $\mathrm{CO}$ of different electrocatalysts can be correlated through equation $8: 3,31$

$\mathrm{K}_{22}^{*}=\frac{2 \mathrm{I}_{m / z 22, \mathrm{CO}}}{\mathrm{I}_{\mathrm{f}, \mathrm{CO}}}$

wherein $I_{m / z 22, \mathrm{Co}}$ is the ionic current of the mass/charge 
signal $m / z 22 ; \mathrm{I}_{\mathrm{f}, \mathrm{CO}}$ is the faradaic current of the $\mathrm{CO}$ stripping; 2 is the number of electrons exchanged during $\mathrm{CO}$ electrooxidation into $\mathrm{CO}_{2}$; and $\mathrm{K}_{22}^{*}$ is the calibration constant of signal $\mathrm{m} / \mathrm{z} 22$, which is required to quantify part of the current deriving from ethanol electrooxidation into $\mathrm{CO}_{2} \cdot{ }^{30,31}$ The $\mathrm{K}_{22}^{*}$ values of different electrocatalysts used in the present study are shown in Table 5.

Table 5. $\mathrm{K}_{22}^{*}$ values of different electrocatalysts

\begin{tabular}{lc}
\hline Electrocatalyst & $\mathrm{K}_{22}^{*}$ \\
\hline $\mathrm{Pt} / \mathrm{C}$ & $1.99 \times 10^{-6}$ \\
$\mathrm{Pt} 80 \mathrm{Rh} 20 / \mathrm{C}$ & $2.95 \times 10^{-6}$ \\
$\mathrm{Pt} 80 \mathrm{Ru} 20 / \mathrm{C}$ & $2.73 \times 10^{-6}$ \\
\hline
\end{tabular}

$\mathbf{K}_{22}^{*}$ : calibration constant of signal $\mathrm{m} / \mathrm{z}, 22$.

\section{Ethanol oxidation reaction (EOR)}

It is known that the EOR into $\mathrm{CO}_{2}$ (at balance $12 \mathrm{e}^{-}$per ethanol molecule) can be incomplete due to different paths. Such result leads to acetaldehyde (at balance $2 \mathrm{e}^{-}$per ethanol
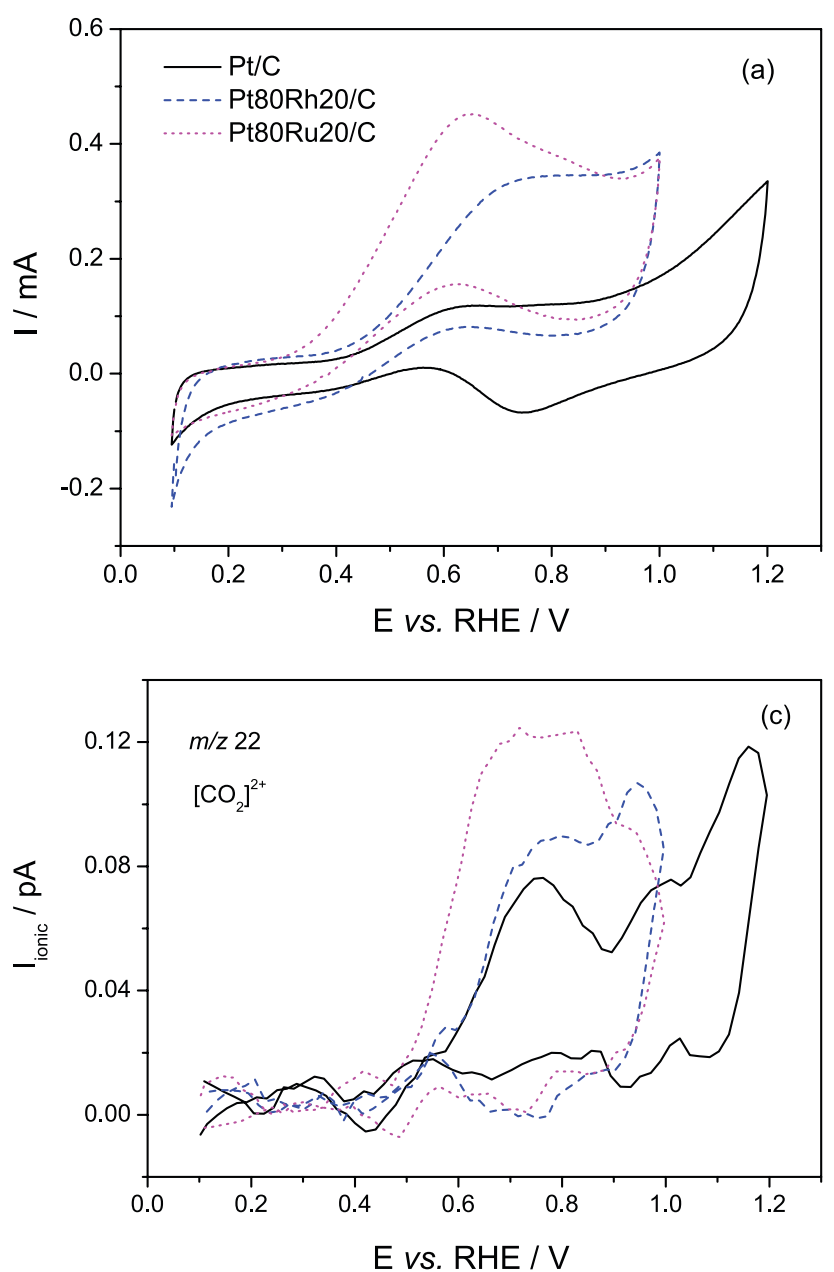

molecule) and acetic acid (at balance $4 \mathrm{e}^{-}$per ethanol molecule) formation. The kinetic mechanisms involved in EOR have been widely studied. $3,27,31$

Thus, products from the electrooxidation reaction of babassu coconut mesocarp ethanol using $\mathrm{Pt} / \mathrm{C}$, Pt80Rh20/C and Pt80Ru20/C electrocatalysts were monitored through online DEMS. The $\mathrm{CO}_{2}$ formation was monitored through mass/charge signal $\mathrm{m} / \mathrm{z} 22$, which corresponds to the double ionized ion $\left[\mathrm{CO}_{2}\right]^{2+}$. Acetaldehyde formation was followed by signal $\mathrm{m} / \mathrm{z}, 29$, which corresponds to [CHO $]^{+} .3,27,31$

Figure 7 shows the cyclic voltammograms of DEMS recorded during electrooxidation experiments involving carbamate coconut mesocarp ethanol at $0.1 \mathrm{~mol} \mathrm{~L}^{-1}$ in $0.5 \mathrm{~mol} \mathrm{~L}^{-1} \mathrm{H}_{2} \mathrm{SO}_{4}$ acid medium, in the synthesized electrocatalysts Pt/C, Pt80Rh20/C and Pt80Ru20/C. These results evidence that bimetallic electrocatalysts present higher current densities and initiate potential ethanol oxidation at $0.3 \mathrm{~V}$, on average, whereas $\mathrm{Pt} / \mathrm{C}$ monometallic electrocatalyst initiates ethanol oxidation at potential $0.4 \mathrm{~V}$,
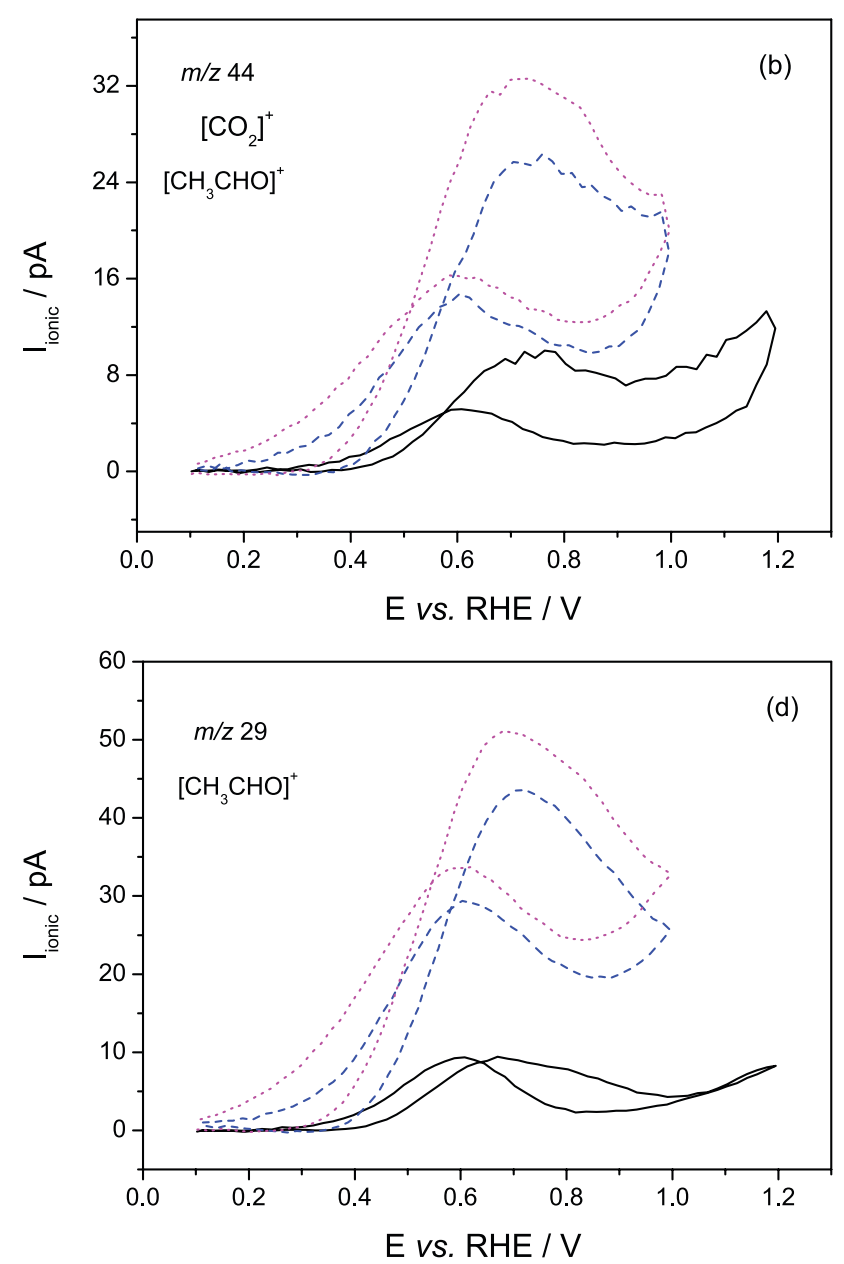

Figure 7. (a) Faradaic currents recorded for $\mathrm{CO}_{2}$ formation. Ionic currents of (b) $\left[\mathrm{CO}_{2}\right]^{+}(\mathrm{m} / \mathrm{z} 22)$ and signals of acetaldehyde, (c) $[\mathrm{CO}]^{2+}(\mathrm{m} / \mathrm{z}, 44)$, and (d) $\left[\mathrm{CH}_{3} \mathrm{CHO}\right]^{+}(\mathrm{m} / z, 29)$, in order to oxidize $0.1 \mathrm{~mol} \mathrm{~L}^{-1}$ babassu coconut mesocarp ethanol in different electrocatalysts. 
on average. Such phenomenon can be explained by the fact that the dehydrogenation process more often occurs in bimetallic electrocatalysts. . $^{3,27,31}$

Figure 7 shows mass signals $m / z 22,29$, and 44 , which were analyzed through DEMS during babassu coconut mesocarp ethanol oxidation reaction experiments. Results show that $\mathrm{CO}_{2}\left(\mathrm{~m} / \mathrm{z}, 22,\left[\mathrm{CO}_{2}\right]^{2+}\right)$ formation starts at $0.5 \mathrm{~V}$, on average, in all the used electrocatalysts. These electrocatalysts present ionic current values at potential close to $0.8 \mathrm{~V}$, but the bimetallic electrocatalysts record higher ionic current densities.

On the other hand, acetaldehyde formation, accompanied by signal $\mathrm{m} / \mathrm{z} 29$, which corresponds to the $[\mathrm{CHO}]^{+}$ fragment, starts at potentials lower than $0.4 \mathrm{~V}$. It presents ionic current densities higher than the ionic current densities attributed to $\mathrm{CO}$ formation. The bimetallic electrocatalysts Pt80Rh20/C and Pt80Rh20/C stand out in relation to the $\mathrm{Pt} / \mathrm{C}$ monometallic electrocatalyst. All the electrocatalysts presented maximum near-current densities of approximately $0.7 \mathrm{~V}$. These results show that acetaldehyde $\left(\mathrm{m} / z, 29[\mathrm{CHO}]^{+}\right)$is the major product in the process of alcohol oxidation of babassu coconut mesocarp, since this product presented higher currents and initiation of potential formation smaller than those shown for the $\mathrm{CO}_{2}$ signals. ${ }^{27}$

The $\mathrm{CO}_{2}$ current efficiency in the different herein used electrocatalysts was set based on the faradaic and ionic current values recorded during babassu coconut mesocarp ethanol oxidation reaction through equation 9:3,27,31

$\mathrm{Aq}_{\mathrm{CO}_{2}}=\frac{6 \mathrm{I}_{m / 222}}{\mathrm{~K}_{22}^{*} \mathrm{I}_{\mathrm{f}}}$

wherein $\mathrm{Aq}_{\mathrm{CO}_{2}}$ is the $\mathrm{CO}_{2}$ current efficiency expressed in percentage; the factor 6 refers to the number of electrons needed for the formation of one $\mathrm{CO}_{2}$ molecule from ethanol; $\mathrm{I}_{m / z} 22$ is the ion current corresponding to the signal $\mathrm{m} / \mathrm{z}, 22$; If is the faradaic current resulting from the ethanol oxidation reaction; and $\mathrm{K}_{22}^{*}$ is the calibration constant of signal $\mathrm{m} / \mathrm{z}, 22.3,27,28$

The $\mathrm{CO}_{2}$ current efficiency results, $\mathrm{Aq}_{\mathrm{CO}_{2}}$, of different electrocatalysts used during the oxidation reaction of babassu coconut mesocarp alcohol are shown in Table 6.

The values shown in Table 6 show that electrocatalysts $\mathrm{Pt} / \mathrm{C}, \mathrm{Pt} 80 \mathrm{Rh} 20 / \mathrm{C}$ and Pt80Ru20/C contain $\mathrm{CO}_{2}$ current efficiency below $1 \%$. It evidences that the largest portion of babassu coconut mesocarp ethanol oxidation is formed by acetaldehyde, which has less environmental impact than the $\mathrm{CO}_{2}$ released into the atmosphere during fuel burning. Studies such as that by Queiroz et al. ${ }^{27}$ present $\mathrm{CO}_{2}$ efficiency calculations performed through DEMS
Table 6. Effective current rate of $\mathrm{CO}_{2}\left(\mathrm{Aq}_{\mathrm{co}_{2}}\right)$ during the electrooxidation of babassu coconut mesocarp ethanol at concentration of $0.1 \mathrm{~mol} \mathrm{~L}^{-1}$ in different synthesized electrocatalysts

\begin{tabular}{lc}
\hline Electrocatalyst & $\mathrm{Aq}_{\mathrm{CO}_{2}} / \%$ \\
\hline $\mathrm{Pt} / \mathrm{C}$ & 0.65 \\
$\mathrm{Pt} 80 \mathrm{Rh} 20 / \mathrm{C}$ & 0.40 \\
$\mathrm{Pt} 80 \mathrm{Ru} 20 / \mathrm{C}$ & 0.60 \\
\hline
\end{tabular}

$\mathrm{Aq}_{\mathrm{CO}_{2}}: \mathrm{CO}_{2}$ current efficiency.

to assess commercial ethanol oxidation. It was done by using different platinum-based electrocatalysts values, and between 2 and $20 \%$ of currents are attributed to $\mathrm{CO}_{2}$ formation, which suggests that the oxidation of commercial ethanol using platinum-based electrocatalysts leads to $\mathrm{CO}_{2}$ formation up to 20 times higher than the babassu coconut mesocarp ethanol oxidation using the same electrocatalyst types. ${ }^{27}$ The research shows the oxidation of babassu coconut mesocarp ethanol is low polluting.

\section{Conclusions}

The method to prepare the electrocatalysts proved to be very effective and of good metal dispersion on the Vulcan carbon support. The bimetallic electrocatalysts showed better performance than the $\mathrm{Pt} / \mathrm{C}$ monometallic catalyst when it comes to the oxidation reaction of the alcohols assessed in acid medium. The bimetallic electrocatalysts Pt80Rh20/C and Pt80Ru20/C presented very approximate compositions of the values obtained by EDX, the largest active areas and the best catalytic activity, thus demonstrating that the addition of a second metal to platinum helps get better electrocatalyst performance.

DEMS studies showed that all electrocatalysts assessed during the alcohol oxidation reaction of babassu mesocarp presented $\mathrm{CO}_{2}$ current efficiency close to $1 \%$. It means that most evaluated ethanol oxidation products are acetaldehyde, which is less harmful to the environment than $\mathrm{CO}_{2}$ released during the oxidations of fuels.

Results recorded in the present study show that babassu coconut mesocarp ethanol has potential to be used in fuel cells. Due to its ability to oxidize producing small amount of $\mathrm{CO}_{2}$ and higher amount of acetaldehyde, it is less harmful to the environment. In addition, babassu coconut ethanol has similar behavior to commercial ethanol in terms of its energy density.

\section{Acknowledgments}

The authors are grateful to the support given by Coordenação de Aperfeiçoamento de Pessoal de Nível 
Superior (CAPES), to Fundação de Amparo à Pesquisa e ao Desenvolvimento Científico e Tecnológico do Maranhão (FAPEMA), to Universidade Federal do Maranhão (UFMA), to Núcleo de Combustível, Catálise e Ambiental (NCCA-UFMA) and to the Electrochemistry Group (GELQ-UFMA).

\section{References}

1. Bozba, S. E.; Erkey, C.; J. Supercrit. Fluids 2012, 62, 1.

2. Prado, A. G. S.; Quim. Nova 2003, 26, 738.

3. Rizo, R.; Sebastián, D.; Lázaro, M. J.; Pastor, E.; Appl. Catal., B 2017, 200, 254.

4. http://www.anp.gov.br/wwwanp/producao-de-biocombustiveis/ etanol, accessed in March 2018.

5. Maciel, A. P.; Biocombustíveis de Babaçu: Ensaio Técnico sobre Oportunidades de Produção de Biocombustíveis a Partir do Coco Babaçu, 1ª ed.; EDUFMA: São Luís, 2016, ch. 21.

6. Zheng, Y.; Yu, C.; Cheng, Y.; Lee, C.; Simmons, C.; Dooley, T.; Zhang, R.; Jenkins, R.; Vander Gheyns, J.; Appl. Energy 2013, 93, 168.

7. Chen, J. P.; Wu, K. W.; Fukuda, H.; Appl. Biochem. Biotechnol. 2008, 145, 59.

8. Sanches, O. J.; Cardona, C. A.; Bioresour. Technol. 2008, 99 , 5270 .

9. Zanin, G. M.; Appl. Biochem. Biotechnol. 2000, 84-86, 1147.

10. Robertson, G. H.; J. Agric. Food Chem. 2005, 54, 353.

11. Tester, R. F.; Qi, X.; Karkalas, J.; Anim. Feed Sci. Technol. 2006, $130,39$.

12. Ribeiro, J.; dos Anjos, D. M.; Kokoh, K. B.; Countanceau, C.; Léger, J. M.; Olivi, P.; de Andrade, A. R.; Tremiliosi-Filho, G.; Electrochim. Acta 2007, 52, 6997.

13. Maksic, A.; Smiljanic, M.; Miljanic, S.; Rakocevic, Z.; Strbac, S.; Electrochim. Acta 2016, 209, 323.

14. An, L.; Chen, R.; J. Power Sources 2016, 329, 484.

15. An, L.; Zhao, T. S.; Li, Y. S.; Renewable Sustainable Energy Rev. 2015, 50, 1462.
16. An, L.; Zhao, T. S.; J. Power Sources 2017, 341, 199.

17. Camara, G. A.; Iwasita, T.; J. Electroanal. Chem. 2005, 578, 315 .

18. Lima, F. H. B.; Profeti, D.; Lizcano-Valbuena, W. H.; Ticianelli, E. A.; Gonzalez, E. R.; J. Electroanal. Chem. 2008, 617, 121.

19. Granja, D. S. S.; Silva, L. M.; Rodrigues, I. A.; Rev. Virtual Quim. 2015, 7, 1635.

20. Zhow, W. J.; Song, S. Q.; Li, W. Z.; Zhou, Z. H.; Sun, G. Q.; Xin, Q.; Douvartzides, S.; Tsiakaras, P.; J. Power Sources 2005, 140,50 .

21. Vigier, F.; Contancean, C.; Hahn, F.; Belgsir, E. M.; Lamy, C.; J. Electroanal. Chem. 2004, 563, 81.

22. Greeley, J.; Nørskov, J. K.; Mavrikakis, M.; Annu. Rev. Phys. Chem. 2002, 53, 319.

23. Zhang, J.; Vukmirovic, M. B.; Xu, Y.; Mavirikakis, M.; Adzic, R.; Angew. Chem., Int. Ed. 2005, 44, 2132.

24. Neto, A. O.; Dias, R. R.; Ribeiro, V. A.; Spinacé, E. V.; Linardi, M.; Eclet. Quim. 2006, 31, 81.

25. Pech-Rodrígues, W. J.; González-Quijano, D.; Vargas-Gutiérrez, G.; Morais, C.; Appl. Catal., B 2017, 203, 654.

26. Nart, F. C.; Vielstich, W. In Handbook of Fuel Cells: Fundamentals, Technology and Applications; Vielstich, W.; Gasteiger, H. A.; Lamm, A.; Yokokawa, H., eds.; John Wiley \& Sons: Chichester, 2003, p. 302-315.

27. Queiroz, A. C.; Silva, W. O.; Rodrigues, I. A.; Lima, F. H. B.; Appl. Catal., B 2014, 160-161, 423.

28. Cantane, D. A.; Ambrosio, W. F.; Chatanet, M.; Lima, F. H. B.; J. Electroanal. Chem. 2012, 681, 56.

29. dos Santos, V. P.; Tremiliosi Filho, G.; Quim. Nova 2001, 24, 856.

30. Deupeuch, A. B.; Maillard, F.; Chatenet, M.; Soudant, P.; Cremers, C.; Appl. Catal., B 2016, 181, 672.

31. Florés-Motaño, J.; García, G.; Guillén-Villafuerte, O.; Rodríguez, J. L.; Planes, G. A.; Pastor, E.; Electrochim. Acta 2016, 209, 121.

32. de Souza, J. P. I.; Queiroz, S. L.; Nart, F. C.; Quim. Nova 2000 , 23,384 . 